\title{
Surveillance for Lyme disease in Canada, 2009 to 2012
}

\author{
Ogden $\mathrm{NH}^{1^{*}}$, Koffi $\mathrm{JK}^{1}$, Lindsay $\mathrm{LR}^{2}$, Fleming $\mathrm{S}^{3}$, Mombourquette $\mathrm{DC}^{3}$, Sanford $\mathrm{C}^{4}$, Badcock $\mathrm{J}^{5}$ \\ Gad RR ${ }^{5}$, Jain-Sheehan $N^{6}$, Moore $S^{6}$, Russell $C^{6}$, Hobbs $L^{6}$, Baydack $R^{7}$, Graham-Derham $S^{7}$, \\ Lachance $\mathrm{L}^{8}$, Simmonds $\mathrm{K}^{8}$, Scott $\mathrm{AN}^{8}$
}

${ }^{1}$ Centre for Food-borne, Environmental and Zoonotic Infectious Diseases, Public Health Agency of Canada, Ottawa, ON

${ }^{2}$ National Microbiology Laboratory, Public Health Agency of Canada, Winnipeg, MB

${ }^{3}$ Public Health Branch, Nova Scotia Department of Health and Wellness, Halifax, NS

${ }^{4}$ Population Health Assessment and Surveillance, Prince Edward Island Department of Health and Wellness, Charlottetown, PE

${ }^{5}$ Office of the Chief Medical Officer of Health, New Brunswick Department of Health, NB

${ }^{6}$ Enteric, Zoonotic and Vector-Borne Diseases, Public Health Ontario, Toronto, ON

${ }^{7}$ Communicable Disease Control Branch, Manitoba Health Healthy Living and Seniors, Winnipeg, MB

${ }^{8}$ Surveillance and Assessment Branch, Alberta Health, Calgary, AB

*Correspondence: Nicholas.ogden@phac-aspc.gc.ca

\section{Abstract}

Objectives: To summarize the first four years of national surveillance for Lyme disease in Canada from 2009 to 2012 and to conduct a preliminary comparison of presenting clinical manifestations in Canada and the United States

Methods: The numbers and incidence of reported cases by province, month, year, age and sex were calculated. Logistic regression was used to examine trends over time. Acquisition locations were mapped and presenting clinical manifestations reported for jurisdictions where data was available. Variations by province, year, age and sex as well as presenting clinical symptoms were explored by logistic regression. An initial comparative analysis was made of presenting symptoms in Canada and the United States.

Results: The numbers of reported cases rose significantly from 144 in 2009 to 338 in 2012 (coefficient $=0.34$, standard error $=0.07, \mathrm{P}<0.05$ ), mostly due to an increased incidence of infections acquired in Canada. More cases were classified as 'confirmed' $(71.5 \%)$ than 'probable' $(28.5 \%)$. Most cases occurred in locations where vector tick populations were known to be present. More men than women were affected $(53.4 \%$ versus $46.6 \%)$, incidence was highest in adults aged 55 to 74 years and in children aged five to 14 years. Most cases (95\%) were acquired from April to November. Of cases acquired in endemic areas, $39.7 \%$ presented with manifestations of early Lyme disease, while $60.3 \%$ had manifestations of disseminated Lyme disease. There were significant differences among age groups, sexes and provinces in the frequencies of reported clinical manifestations. The proportion of cases acquired in endemic areas presenting with early Lyme disease was lower than that reported in the US.

Conclusion: Lyme disease incidence is increasing in Canada. Most cases are acquired where vector tick populations are spreading and this varies geographically within and among provinces. There is also variation in the frequency of age, season and presenting manifestations. The lower proportion of cases presenting with early Lyme disease in Canada compared with the US suggests lower awareness of early Lyme disease in Canada, but this requires further study.

\section{Introduction}

Lyme disease, caused by the bacterium Borrelia burgdorferi sensu stricto in North America is transmitted to humans from wild animal reservoir hosts by Ixodes spp. ticks (1) in their woodland habitats (2). Lyme disease risk in Canada occurs where tick vectors are established in southern British Columbia (where the relatively inefficient tick vector Ixodes pacificus occurs) and in southern parts of central and eastern Canada into which the efficient tick vector I. scapularis is spreading from the United States, driving Lyme disease emergence in Canada (3). Low- 
level Lyme disease risk occurs over a wider geographic area due to ticks dispersed from tick populations by migratory birds $(4,5)$.

In light of the documented northern migration of ticks into Canada, Lyme disease became nationally notifiable in Canada in 2009 and basic information on human cases is submitted by all provinces and territories to the National Notifiable Disease Surveillance System (NNDSS) coordinated by the Public Health Agency of Canada (PHAC). A Lyme Disease Enhanced Surveillance (LDES) system was initiated by PHAC in 2010 with provincial public health organizations to obtain more detailed data on Lyme disease cases. Together, these surveillance systems aim to identify changing trends in Lyme disease incidence, the Canadian population at risk and the types of clinical disease in Canada to inform clinician-based Lyme disease diagnosis and reporting.

In this study, data from the first four years of national surveillance for Lyme disease (2009 to 2012) are presented and analyzed to describe the early patterns of Lyme disease emergence in Canada. As Lyme disease emergence in central and eastern Canada is likely an extension of the emergence of Lyme disease in the US, patterns of Lyme disease cases (age, season of acquisition and presenting manifestations) were compared against those reported in the United States.

\section{Methods}

\section{Human case data sources}

NNDS data on annual numbers of cases reported to all provincial and territorial public health organizations by clinicians or via provincial laboratories were available for 2009 to 2012. Basic information reported included sex, age and episode date. The cases were classified as 'confirmed' or 'probable' by the provincial public health organizations submitting the data, except for British Columbia, Québec and New Brunswick who reported all cases without classifying them and did not report cases with erythema migrans rashes without laboratory support for the diagnosis.

\section{The national surveillance case definition of Lyme disease (6)}

\section{Confirmed case}

Clinical evidence of illness with laboratory confirmation by:

- Isolation of Borrelia burgdorferi from an appropriate clinical specimen, OR

- Detection of $B$. burgdorferi DNA by polymerase chain reaction, OR

- A positive serologic test result using the two-tier (ELISA and Western Blot) test with a history of residence in or visit to a Lyme disease-endemic area. ${ }^{*}$

\section{Probable case}

P1 = Clinical evidence of illness with a positive serologic test result using the two-tier (ELISA and Western Blot) test, without a history of residence in, or visit to, a Lyme disease endemic area*

OR

P2 = Clinician-observed erythema migrans without laboratory evidence but with history of residence in, or visit to, a Lyme disease endemic area. ${ }^{1}$

${ }^{1}$ Lyme disease endemic areas are locations where tick populations have become established (as confirmed by multiple site visits) and are transmitting $B$. burgdorferi among wild animal hosts (7). Increasingly, due to the cost of multiple site visits, environmental risk of Lyme disease is defined as 'risk areas' where tick presence has been detected by field surveillance but not confirmed by multiple site visits (3).

In 2010, the LDES was implemented in partnership with the provinces of Manitoba, Ontario, New Brunswick and Nova Scotia. In 2012, Alberta, Saskatchewan and Prince Edward Island joined. Data transferred in a standard form in the LDES included details of possible location of acquisition of infection within or outside Canada, details of clinical manifestations and methods of laboratory diagnosis. There were variations among provinces participating in the LDES in the data provided (Appendix 1). 


\section{Clinical manifestations}

Information on clinical features was provided by Manitoba, Ontario, New Brunswick and Nova Scotia, although Manitoba reported only two categories of symptoms: erythema migrans and 'other clinical evidence'; i.e., evidence of disseminated Lyme disease but without further details on symptoms. Categories of clinical manifestations were those of early Lyme disease (i.e., erythema migrans), early disseminated Lyme disease including manifestations of neuroborreliosis (Bell's palsy or other neurological manifestations of disseminated Lyme disease), cardiac manifestations and manifestations of late disseminated Lyme disease such as arthritis. (See text box below.) Note that it was assumed that all "P2" probable cases (i.e., cases with erythema migrans but no serological test result) were early Lyme disease having a single erythema migrans rather than multiple erythema migrans lesions (which occur in disseminated Lyme disease). Cases with multiple erythema migranswould be expected to have positive serological test results and be captured as confirmed or "P1" probable cases.

\section{Main manifestations of Lyme disease (8)}

Early localized: Erythema migrans +/- fever, arthralgias and headache

Early disseminated: Multiple erythema migrans $+/$ - fever, arthralgias, headache and lymphadenopathy

Cardiac: AV block, tachyarrhythmias, myopericarditis, myocardial dysfunction

Neurologic: Aseptic meningitis, cranial neuropathy (e.g., Bell's palsy), motor or sensory radiculopathy

Late disseminated: Oligoarticular arthritis

Neurologic: Encephalopathy, axonal polyradiculoneuropathy, chronic encephalomyelitis ${ }^{1}$

${ }^{1}$ Neurological manifestations of late Lyme disease are very uncommon (9), so for parsimony in collection and transfer of data, all cases of Lyme disease with neurological manifestations were considered as early disseminated Lyme disease.

\section{Data analyses}

The data from both the LDES and NNDSS were summarized and, where possible, compared against similar data on Lyme disease case surveillance from the US (10) where similar data have been collected for over 20 years.

Annual incidence in Canada, as well as province-, sex- and age group-specific incidence rates was calculated per 100,000 population. The denominators were census population estimates for July 1st for each year from 2009 to 2012 (11). The proportion of cases reported by month and by case classification for each year was also calculated. Trends in the numbers of cases reported nationally for the period 2009 to 2012 ('confirmed' and 'probable' cases combined) were explored by logistic regression using weighted least squares estimation in Stata SE 11.0 for Windows (College Station, Tx), with year as the explanatory variable accounting for recent Canadian population estimates (12). Analysis was conducted with case numbers and data reported at the time but these may change slightly due to retrospective identification of cases.

Analysis of numbers of endemic versus travel-related cases, location of acquisition and clinical features were performed on cases reported via the LDES by Manitoba, Ontario, New Brunswick and Nova Scotia. The likely locations of exposure of cases in Canada were mapped using ArcGIS Version 10.2 (ESRI) with point locations being the centroid of Forward Sortation Areas (Table 1) or endemic areas depending on reported location of acquisition. Known endemic areas and risk areas (3) were also mapped for visual comparison. 
Table 1: Lyme disease cases by classification and year, 2009 to 2012

\begin{tabular}{|c|c|c|c|c|c|c|c|c|c|c|}
\hline \multicolumn{11}{|c|}{ Year } \\
\hline \multirow{2}{*}{ Case classification } & \multicolumn{2}{|c|}{2009} & \multicolumn{2}{|c|}{2010} & \multicolumn{2}{|c|}{2011} & \multicolumn{2}{|c|}{2012} & \multicolumn{2}{|c|}{ Total } \\
\hline & $\mathrm{N}$ & $(\%)$ & $\mathrm{N}$ & $(\%)$ & $\mathrm{N}$ & $(\%)$ & $\mathrm{N}$ & $(\%)$ & $N$ & $(\%)$ \\
\hline \multicolumn{11}{|c|}{ All cases } \\
\hline Confirmed & 115 & $(79.9)$ & 107 & $(74.8)$ & 188 & $(70.7)$ & 227 & $(67.2)$ & 637 & (71.5) \\
\hline Probable & 29 & $(20.1)$ & 36 & $(25.2)$ & 78 & $(29.3)$ & 111 & $(32.8)$ & 254 & (28.5) \\
\hline Total & 144 & 100 & 143 & 100 & 266 & 100 & 338 & 100 & 891 & 100 \\
\hline \multicolumn{11}{|c|}{ Cases acquired in Canada with clinical data ${ }^{1}$} \\
\hline Confirmed & 44 & $(81.5)$ & 43 & $(68.3)$ & 79 & $(61.7)$ & 93 & $(65.5)$ & 259 & (66.9) \\
\hline All probable cases & 10 & $(18.5)$ & 20 & (31.7) & 49 & $(38.3)$ & 49 & $(34.5)$ & 128 & (33.1) \\
\hline $\begin{array}{r}\text { First probable case } \\
\text { definition }\end{array}$ & 8 & $(14.8)$ & 15 & $(23.8)$ & 40 & (31.3) & 24 & (16.9) & 87 & (22.5) \\
\hline $\begin{array}{l}\text { Second probable } \\
\text { case definition }\end{array}$ & 2 & $(3.7)$ & 5 & $(7.9)$ & 9 & $(7.0)$ & 25 & $(17.6)$ & 41 & $(10.6)$ \\
\hline Total & 54 & 100 & 63 & 100 & 128 & 100 & 142 & 100 & 387 & 100 \\
\hline
\end{tabular}

Cases for which detailed clinical data (symptoms and laboratory diagnosis information) and exposure information was available to distinguish the two different probable case definitions.

Variations among provinces, years, age groups and sex in the proportions reporting different clinical manifestations of disseminated Lyme disease were explored in logistic regression models in Stata SE 11.0. The outcome variables were presence/absence of erythema migrans, neurological manifestations, cardiac manifestations and arthritis/joint swelling in separate models. Explanatory variables of age, year, province and sex were first explored in bivariable analyses and those showing associations with the outcome at a level of significance of $P<0.1$ were included in multivariable models. Polynomial relationships of age with frequency of manifestations (using age and age squared as explanatory variables) were explored as suggested by visual inspection of Lowess smoothed graphs of these relationships. The most parsimonious multivariable models were sought by backward elimination of variables. The level of significance for the multivariable model was $P<0.05$.

\section{Results}

\section{Incidence and temporal trends}

The numbers of reported cases rose significantly from 144 in 2009 to 338 in 2012 (coefficient $=0.34$, standard error $=0.07, \mathrm{P}<0.05$; Table 1), with incidence rising from 0.4 to 1.0 per 100,000 population (Table 2). 
Table 2: Incidence of reported Lyme disease cases by province and year, 2009 to 2012

\begin{tabular}{|l|c|c|c|c|}
\hline \multirow{2}{*}{ Province } & \multicolumn{4}{c|}{ Year } \\
\cline { 2 - 5 } & $\mathbf{2 0 0 9}$ & $\mathbf{2 0 1 0}$ & $\mathbf{2 0 1 1}$ & $\mathbf{2 0 1 2}$ \\
\hline \multicolumn{4}{|c|}{ All cases } \\
\hline British Columbia & 0.2 & 0.2 & 0.4 & 0.4 \\
\hline Alberta & 0.0 & 0.0 & 0.2 & 0.2 \\
\hline Saskatchewan & 0.0 & 0.0 & 0.1 & 0.0 \\
\hline Manitoba & 0.4 & 1.0 & 1.0 & 1.5 \\
\hline Ontario & 0.8 & 0.7 & 1.0 & 1.4 \\
\hline Québec & 0.2 & 0.1 & 0.4 & 0.5 \\
\hline Prince Edward Island & 0.0 & 0.0 & 0.7 & 1.4 \\
\hline New Brunswick & 0.0 & 0.3 & 0.7 & 0.9 \\
\hline Nova Scotia & 1.7 & 1.8 & 5.7 & 5.4 \\
\hline Newfoundland and Labrador & 0.0 & 0.2 & 0.0 & 0.0 \\
\hline Canada & 0.4 & 0.4 & 0.8 & 1.0 \\
\hline \multicolumn{2}{|c|}{ Cases acquired in Canada } & & \\
\hline Saskatchewan & 0.0 & 0.0 & 0.1 & 0.0 \\
\hline Manitoba & 0.3 & 0.6 & 0.6 & 1.0 \\
\hline Ontario & 0.5 & 0.5 & 0.8 & 0.8 \\
\hline Prince Edward Island & 0.0 & 0.0 & 0.0 & 0.7 \\
\hline New Brunswick & 0.0 & 0.3 & 0.4 & 0.7 \\
\hline Nova Scotia & 1.5 & 1.5 & 5.2 & 5.3 \\
\hline
\end{tabular}

${ }^{1}$ British Columbia and Québec did not provide information on whether cases were acquired in Canada or during travel outside Canada. All cases in Alberta and Newfoundland and Labrador were all acquired during travel outside Canada.

Cases were reported from all provinces with most infections acquired in Canada occurring in British Columbia, Manitoba, Ontario, Québec, New Brunswick and Nova Scotia. All cases reported from Alberta and Newfoundland and Labrador were reported as acquired during travel outside Canada.

In 2012, incidence was >1.0 per 100,000 population in five provinces; Manitoba, Ontario, New Brunswick, Nova Scotia and Prince Edward Island (Table 2). Incidence increased primarily in Manitoba, Ontario, Québec, New Brunswick and Nova Scotia (Table 2). There was a slight decrease of the number of cases reported in British Columbia and Nova Scotia from 2011 to 2012.

The majority of cases were reported as 'confirmed' (Table 1). Of the cases without a reported history of travel outside Canada, 387 included data on clinical symptoms and likely location of infection. For these cases, (reported by Manitoba, Ontario, New Brunswick and Nova Scotia), the numbers of P1 and P2 'probable' cases could be estimated. For these provinces, most probable cases were of the P1 category (Table 1).

\section{Incidence variation with age and sex}

Incidence varied among age groups, being highest in older adults from 55 to 74 years and in children (those cases with reported ages less than 18) being highest in the five to 14 year age range (Figure 1). More cases were reported as males $(476 / 891,53.4 \%)$ than females $(409 / 891,46.6 \%)$, which was consistent for most $(16 / 18)$ age groups (Figure 1). 
Figure 1: The incidence of reported Lyme disease cases per 100,000 population during 2009 to 2012 by age and sex

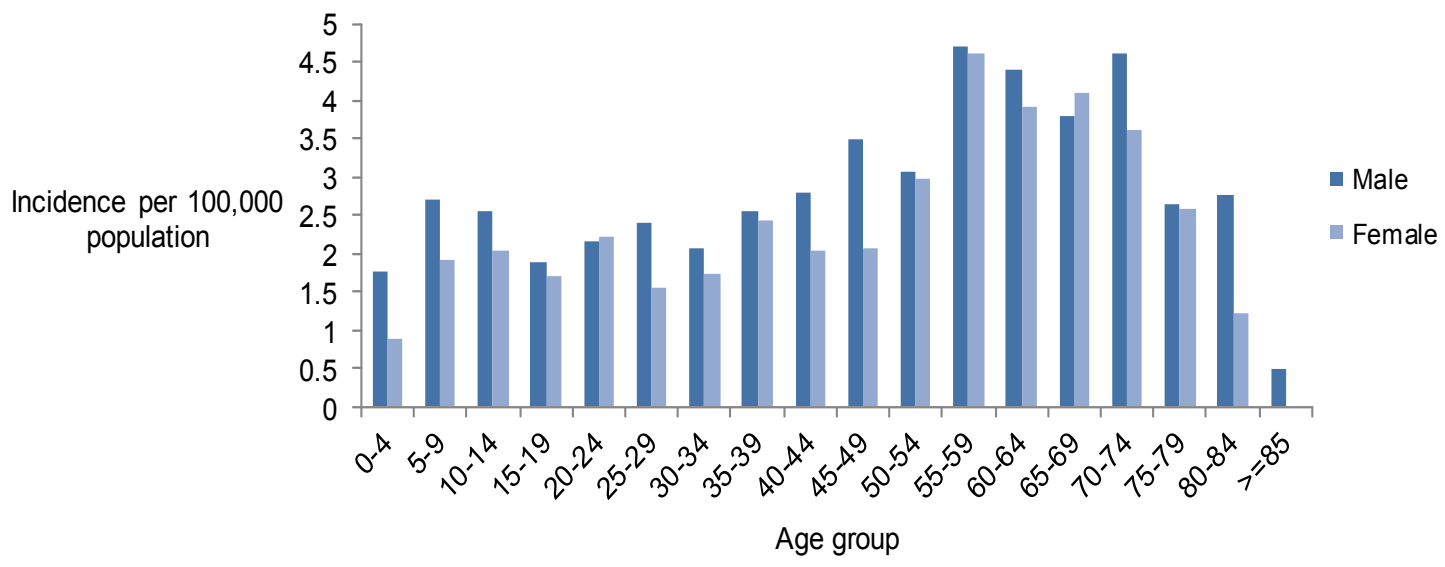

\section{Seasonality}

Of 387 cases for which the type of episode date was recorded, the episode date was date of onset of illness for $328(84.7 \%)$, date of specimen collection for diagnosis for $42(10.8 \%)$, date of clinical or laboratory diagnosis for $13(3.3 \%)$ and date of reporting for $3(0.8 \%)$. Lyme disease cases had episode dates in all months of the year, but most (544/891, 61.1\%) occurred from June to August (Figure 2). Cases in British Columbia tended to occur earlier and later in the year than in other provinces, while a greater proportion of cases occurred in October in Manitoba compared to other provinces (Figure 2).

Figure 2: The proportions of Lyme disease cases reported from 2009 to 2012 and acquired in Canada by episode date ${ }^{1}$

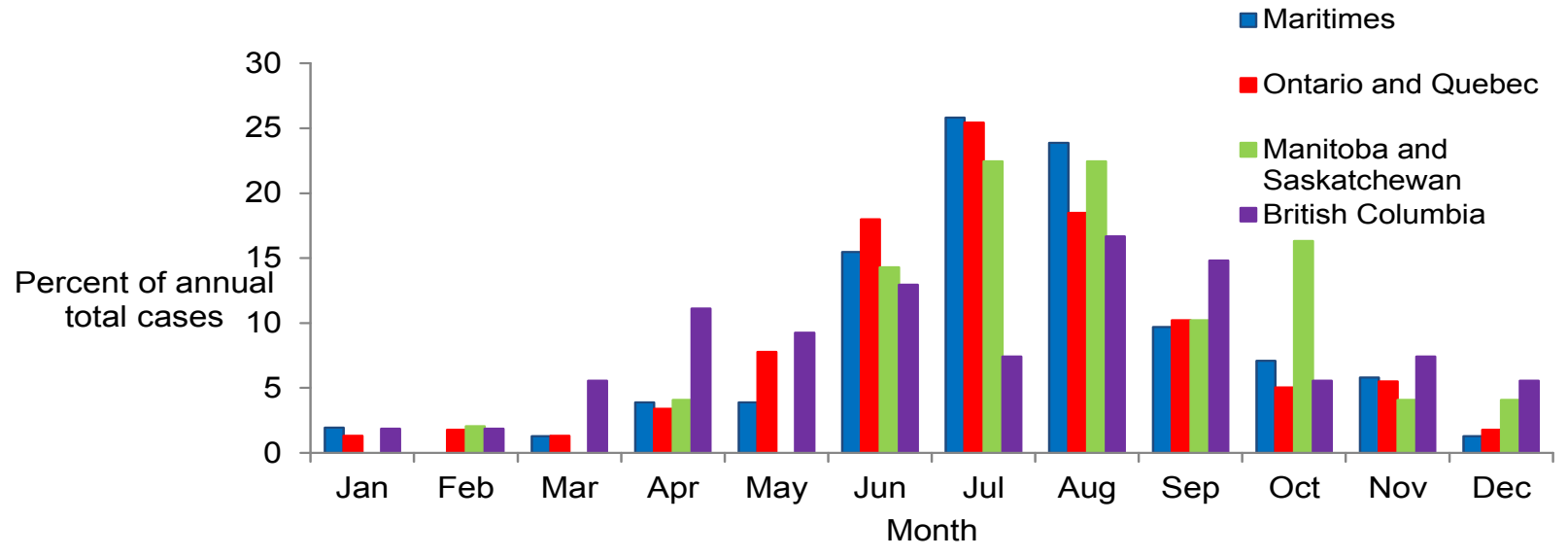

${ }^{1}$ Where date of onset of illness was not available, date of diagnosis or specimen collection for laboratory diagnosis were used as the episode date. 


\section{Geographic location of acquisition}

Most cases acquired in Canada were acquired in areas where known endemic areas or risk areas occur, although cases were reported to occur outside these locations (Figure 3). The annual numbers of cases reported as acquired outside Canada from 2009 to 2012 was stable: between 38 to 48 cases per year from 2009 to 2012 . For the 54 cases reported from 2009 to 2012 for which the location of travel out of Canada was provided, 38 (70.4\%) were acquired in the US and $16(29.6 \%)$ were acquired in Europe.

Figure 3: The reported location of acquisition of Lyme diseases acquired in Canada from 2009 to 2012

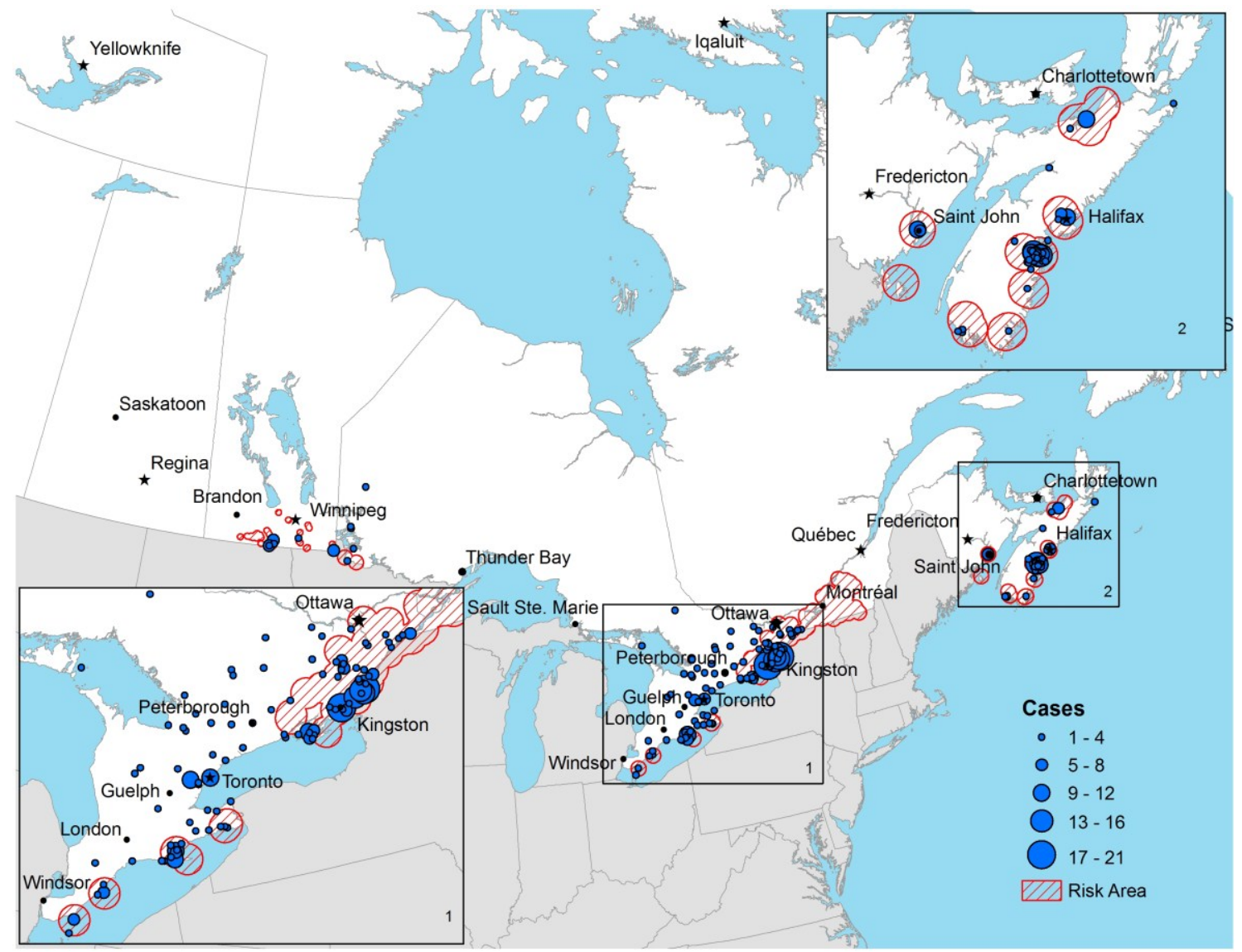

\section{Clinical manifestations}

Of the 353 cases for which information on all five categories of clinical manifestations were available, 157 (44.4\%) reported erythema migrans alone (and were therefore early Lyme disease) and a further 92 reported EM with manifestations of disseminated Lyme disease. Manifestations of early disseminated Lyme disease were reported for 98 cases $(27.8 \%)$ for which the following symptoms were reported: 92 cases $(26.1 \%)$ reported neurological manifestations (Bell's palsy was reported for 30 cases [8.5\%] and other neurological manifestations for 74 cases [21.0\%]) and cardiac manifestations for 17 cases (4.8\%) (Figure 4). Manifestations of late disseminated Lyme disease, e.g., arthritis, were reported for 133 cases (37.8\%) (Figure 4). Multiple manifestations were reported for 131 cases $(37.2 \%)$. Of all the reported cases with disseminated Lyme disease, the proportion of cases reporting neurological, cardiac and arthritis manifestations were respectively $38 \%, 7 \%$ and $55 \%$. 
Figure 4: Percentage of cases reported in the Lyme Disease Enhanced Surveillance with different clinical manifestations of Lyme disease compared against those reported in surveillance in the US $(10)^{1}$

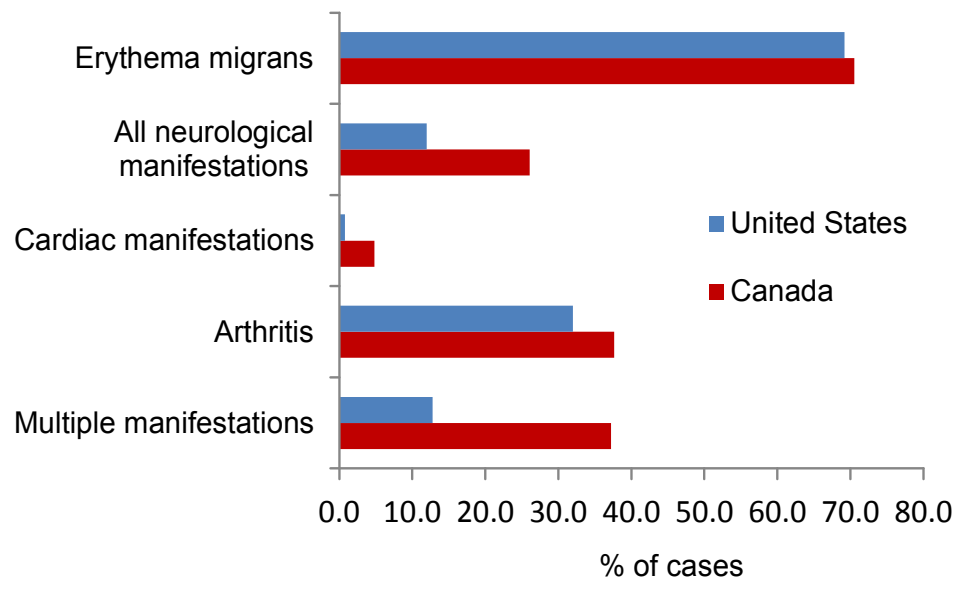

\footnotetext{
${ }^{1}$ Note that the total values for each manifestation are shown and that each case may have reported multiple manifestations. The overall proportion reporting multiple manifestations is shown by the lower pair of bars.
}

According to the surveillance case definitions, cases of early Lyme disease (the "P2" case definition: erythema migrans without laboratory test support for the diagnosis) can only be reported from patients having contact with known Lyme disease-endemic areas. Therefore, to determine the proportions of cases being diagnosed with early Lyme disease versus disseminated Lyme disease (early and/or late), the denominator must be the number of cases with information on clinical manifestations that were reported as having been acquired in known endemic areas. There were 302 cases, with information on clinical manifestations reported as acquired in endemic areas in Manitoba, Ontario, New Brunswick and Nova Scotia. Of these $220(72.8 \%)$ reported erythema migrans, but erythema migrans was the sole manifestation for 120 cases (39.7\%), so only $39.7 \%$ of cases were reported in early Lyme disease, while the rest (60.3\%) had symptoms of disseminated Lyme disease (Figure 5). In New Brunswick, cases of erythema migrans without serological support for the diagnosis are not reported, but for four of the nine cases $(44.4 \%)$ with data on clinical manifestations, erythema migrans was the only clinical manifestation. Therefore possible under-reporting of "P2" probable cases (erythema migrans acquired in an endemic area) in all the provinces was not simply attributable to lack of reporting in New Brunswick. The number of cases during the period 2009 to 2012 from the three provinces reporting information on all five clinical features (Ontario, New Brunswick \& Nova Scotia) was 275. 
Figure 5: The percentage of infections acquired in endemic areas reported at different stages of disease according to the clinical manifestations reported in the Lyme Disease Enhanced Surveillance

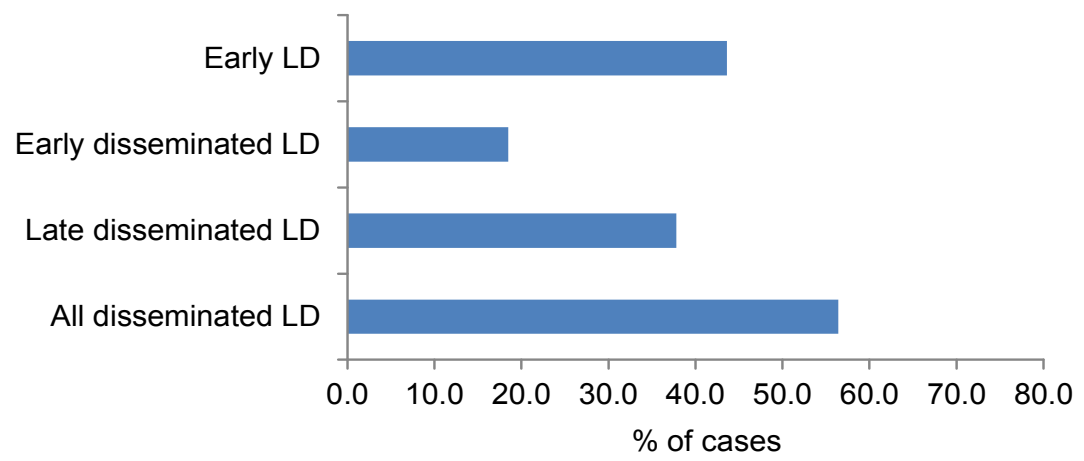

Of the cases acquired in endemic areas, $199(72 \%)$ reported erythema migrans (of which 120 [43.6\%] had erythema migrans as the only clinical manifestation), 25 (9.1\%) had Bell's palsy, $60(21.8 \%)$ had other neurological symptoms (a total of 74 [26.9\%] had neurological symptoms of any kind), $14(5.1 \%)$ had cardiac symptoms and $104(37.8 \%)$ had arthritis or joint swelling. More than one clinical manifestation was reported for $107(38.9 \%)$ cases.

Overall, of cases acquired in endemic areas 120 (43.6\%) were early Lyme disease (reported to have erythema migrans as the only manifestation) and $155(56.4 \%)$ were disseminated Lyme disease. Of the disseminated Lyme disease cases $51(18.5 \%)$ were early disseminated Lyme disease (reported to have neurological or cardiac manifestations but not arthritis) and 104 (37.8\%) were late disseminated Lyme disease (reported to have arthritis).

The frequency of reported erythema migrans was highest for children and adults $>50$ years compared to other age groups, although after adjusting for year, the frequency of reporting of erythema migrans increased linearly with age (Table 3, Figure 6). The frequency of neurological manifestations and cardiac symptom reports varied significantly among age groups. Neurological manifestations were most frequently reported for 20 to 59 year-olds and relatively rarely reported for younger children and adults over 60 , while cardiac symptoms were only seen in cases aged 20 to 69, particularly in cases aged 30 to 49 (Figure 6). The proportion of cases reporting neurological symptoms was also significantly higher in Ontario than in Nova Scotia and New Brunswick combined and was lower in women than men (Table 3). There were no significant differences among ages, sexes, provinces and years in the proportion of cases that reported arthritis (data not shown). 
Table 3: Final multivariable models, following backward elimination of non-significant $(P>0.05)$ variables, for which the outcome variables were the proportion of cases showing erythema migrans, neurological manifestations and cardiac manifestations

\begin{tabular}{|l|c|c|c|c|}
\hline \multicolumn{1}{|c|}{ Variable } & Odds ratio & 95\% Confidence interval & Wald z & P value \\
\hline \multicolumn{2}{|c|}{ Outcome = erythema migrans } \\
\hline Year 2010 versus 2009 & 1.364 & $0.616-3.018$ & 0.77 & $>0.1$ \\
\hline Year 2011 versus 2009 & 2.232 & $1.109-4.489$ & 2.25 & $<0.05$ \\
\hline Year 2012 versus 2009 & 2.860 & $1.416-5.778$ & 2.93 & $<0.01$ \\
\hline Age & 1.015 & $1.004-1.027$ & 2.71 & $<0.01$ \\
\hline \multicolumn{7}{|c|}{ Outcome neurological manifestations } \\
\hline Women versus men & 0.561 & $0.345-0.940$ & -2.19 & $<0.05$ \\
\hline Age & 1.073 & $1.014-1.146$ & 2.45 & $<0.05$ \\
\hline Age squared & 0.998 & $0.998-0.999$ & -0.30 & $<0.01$ \\
\hline $\begin{array}{l}\text { Ontario versus New Brunswick } \\
\text { and Nova Scotia }\end{array}$ & 3.781 & $1.849-7.772$ & 3.62 & $<0.001$ \\
\hline \multicolumn{5}{|l|}{} \\
\hline Age & Outcome cardiac manifestations & & \\
\hline Age squared & 1.305 & $1.043-1.632$ & 2.33 & $<0.05$ \\
\hline
\end{tabular}

Figure 6: Percentage of cases by age group that showed erythema migrans, neurological manifestations, cardiac manifestations or arthritis/joint swelling ${ }^{1}$

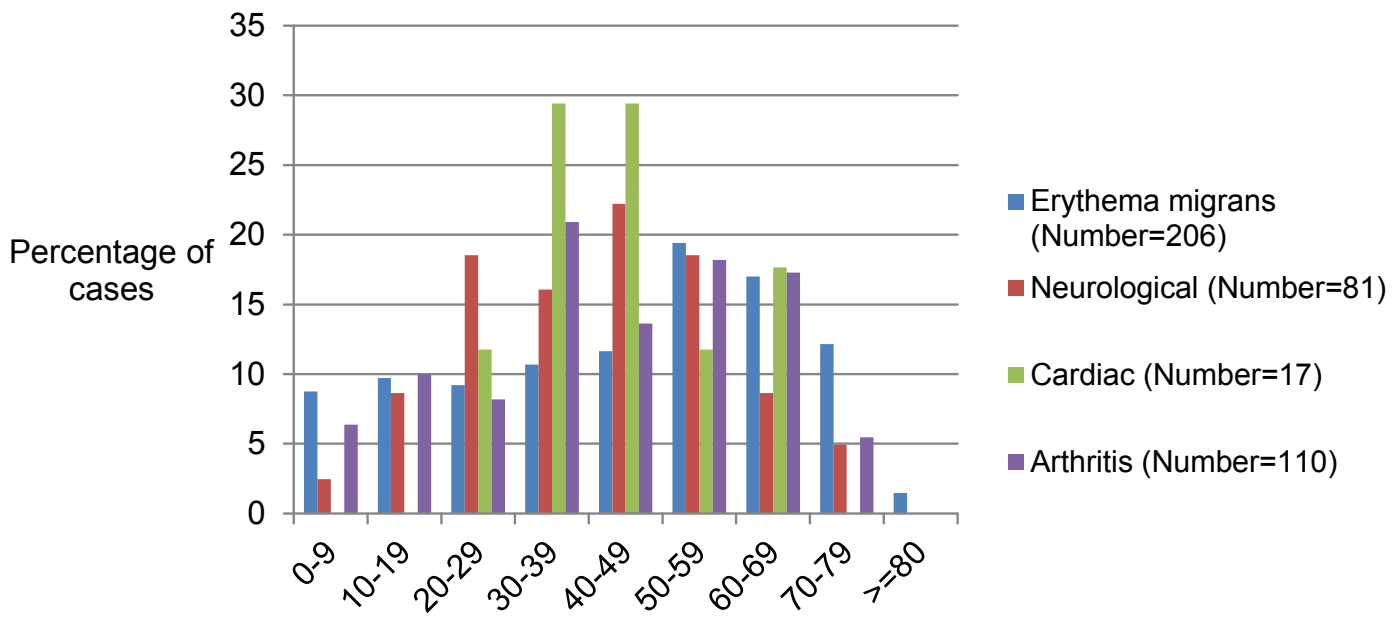

Age group

${ }^{1} \mathrm{~N}$ indicates the number of cases reported as having clinical manifestations.

\section{Discussion}

The annual number of Lyme disease cases reported in Canada more than doubled from 2009 to 2012. Most of this increase was associated with Lyme disease that was acquired in provinces from Manitoba eastward. This trend and the pattern of change in incidence among provinces is consistent with the geographic spread of $I$. scapularis and Lyme disease risk in eastern and central Canada, although increasing awareness among the public and health practitioners may be resulting in a greater proportion of reported cases. The reported number of 
Lyme disease cases is likely an underestimate due to expected under-reporting of Lyme disease in emerging areas (13) and because early Lyme disease cases can be reported only if acquired in Lyme disease-endemic areas unless supported by laboratory evidence. Cases acquired outside these areas are not reported to public health.

Two thirds of Lyme disease cases were 'confirmed' which is consistent with the risk of acquiring Lyme disease being particularly high in Lyme disease-endemic areas. Tick surveillance $(3,14,15)$ shows that the I. scapularis population is expanding its geographic range in Canada and nearly a quarter of reported disseminated Lyme disease cases were acquired in areas not known as endemic areas (and were P1 probable cases). However, most of these cases occurred in 'risk' areas where populations of I. scapularis are emerging (Figure 3). In risk and endemic areas, incidence may be much higher (over 25/100,000) than province-level incidence values (16). A small number of Lyme disease cases occurred where I. scapularis populations are not yet known but where little field surveillance has occurred to date to verify their presence or absence.

The incidence of reported cases among adults was highest in those over 54 years of age, in men and in children under 15 years old. This pattern is consistent with US surveillance (10). These age groups and men may be particularly at risk of acquiring Lyme disease. However, children and older adults reported early Lyme disease manifestations more frequently and manifestations of disseminated Lyme disease less frequently, so high incidence in these groups may reflect greater awareness and earlier presentation for diagnosis compared to younger adults.

The seasonality of cases in Canada was similar to that observed in the US (10) and was consistent with tickborne transmission. I. scapularis and I. pacificus are active from April to November and human outdoor recreational activities in woodlands are also most likely to occur at this time. Nymphal ticks transmit most cases of Lyme disease (17), but cases were acquired in early spring and autumn when adult ticks are most active. Consistent with longer season activity of I. pacificus compared to I. scapularis (18), more cases occurred earlier and later in the year in British Columbia where I. pacificus is the vector. Delays between infection and onset or diagnosis of disseminated Lyme disease could explain reporting of some cases in winter (9), although some early Lyme disease cases had a reported date of onset in winter. Why more Lyme disease cases were reported in autumn in Manitoba compared to other provinces in unclear, as ticks would also be active in other provinces at this time.

Data on the types of Lyme disease cases reported from endemic areas suggests there is suboptimal awareness of Lyme disease among the public and front line medical practitioners. A history of erythema migrans was reported for $>80 \%$ of cases acquired in known endemic areas. However only $40 \%$ of cases were reported during early Lyme disease and $60 \%$ were likely disseminated Lyme disease, even though erythema migrans was recorded as a manifestation in many disseminated Lyme disease cases. This suggests that many reported cases of disseminated Lyme disease could have been diagnosed and treated earlier, but either the affected patients did not know what the erythema migrans rash was (and didn't present themselves for diagnosis at this stage) or medical practitioners did not diagnose and treat the cases at this stage. In the US, where awareness among the public and medical practitioners is expected to be greater, $>56 \%$ of reported cases were early Lyme disease (10).

Overall proportions of clinical manifestations of disseminated Lyme disease cases in Canada were similar to those in the United States. When the proportions of disseminated Lyme disease cases showing neurological manifestations, cardiac manifestations and arthritis (i.e., late Lyme disease) were compared against similar data from the US (10), there were some differences. The proportions that were late disseminated Lyme disease were similar (55\% and $50 \%$ for Canada and the US respectively), but the proportion of cases reporting neurological symptoms was lower in Canada (38\% versus $47 \%$ in the US) and the proportion reporting cardiac manifestations was higher in Canada ( $7 \%$ versus $3 \%$ in the US). Additional Canadian surveillance data is required to determine whether this is a consistent difference and if it changes over time. Tracking occurrence of Lyme carditis is also important because it has been associated with sudden deaths (19).

Neurological and cardiac manifestations were more likely to be reported for younger adults whereas there was no evidence of age-associated variations in the frequency of reporting arthritis. Neurological manifestations were less likely to be reported for males than females. The reasons for these observations are not clear and require further exploration. Reporting of neurological symptoms was more common in Ontario than the Maritimes possibly due to 
different methods of reporting symptoms among provinces or due to geographic variation in $B$. burgdorferi strains (20).

The observations and results of this study represent a first view of Lyme disease surveillance data in Canada and it is too early to make firm conclusions regarding these preliminary trends. It is possible that data on location of acquisition and manifestation of infection in Canada is affected by issues of recall and other inaccuracies. The findings here require further study to be corroborated and to assess causality.

\section{Conclusion}

These data suggest that Lyme disease is emerging in Canada, with most cases occurring in seasons when and locations where Lyme disease risk in the environment is known to occur. Incidence was higher in men, in adults over 54 years old and children under 15 years old. The proportion of cases reported in early Lyme disease was lower than expected suggesting suboptimal awareness of Lyme disease during the surveillance period. Variations among provinces and age groups in the proportions of cases reporting erythema migrans and neurological and cardiac manifestations of disseminated Lyme disease were found, although are at present unexplained.

\section{Acknowledgements}

The authors thank Yann Pelcat of PHAC for preparing Figure 3.

\section{Conflict of interest}

None

\section{References}

(1) Ogden NH, Lindsay RL, Sockett PN, Morshed M, Artsob H. Emergence of Lyme disease in Canada. CMAJ. 2009;180:1221-4.

(2) Kurtenbach K, Hanincová K, Tsao J, Margos G, Fish D, Ogden NH. Key processes in the evolutionary ecology of Lyme borreliosis. Nat Rev Microbiol. 2006;4:660-9.

(3) Ogden NH, Koffi, JK, Pelcat Y, Lindsay LR. Environmental risk from Lyme disease in central and eastern Canada: A summary of recent surveillance information. Can Commun Dis Rep. 2014;40:74-82.

(4) Ogden NH, Lindsay RL, Hanincová K, Barker IK, Bigras-Poulin M, Charron DF, et al. The role of migratory birds in introduction and range expansion of Ixodes scapularis ticks and Borrelia burgdorferi and Anaplasma phagocytophilum in Canada. Appl Environ Microbiol. 2008;74:1780-90.

(5) Vrbova L, Middleton D. Descriptive epidemiology of Lyme disease in Ontario: 1999-2004. Can Commun Dis Rep. 2006;32:247-57.

(6) Public Health Agency of Canada. Case definitions for communicable diseases under national surveillance. Can Commun Dis Rep. 2009;35:S2.

(7) Canadian Public Health Laboratory Network. The laboratory diagnosis of Lyme borreliosis: Guidelines from the Canadian Public Health Laboratory Network. Can J Infect Dis Med Microbiol. 2007;18:145-8.

(8) Hatchette TF, Davis I, Johnston BL. Lyme disease: Clinical diagnosis and treatment. Can Commun Dis Rep. 2014;4011:194-208.

(9) Wormser GP, Dattwyler RJ, Shapiro ED, Halperin JJ, Steere AC, Klempner MS, et al. The clinical assessment, treatment, and prevention of Lyme disease, human granulocytic anaplasmosis, and babesiosis: Clinical practice guidelines by the Infectious Diseases Society of America. Clin Infect Dis. 2006;43:1089-134.

(10) Bacon RM, Kugeler KJ, Mead P. Surveillance for Lyme disease United States, 1992-2006. MMWR Surveill Sum. 2008;57:1-9.

(11) Statistics Canada [Internet]. CANSIM census data. 2014. http://www5.statcan.gc.ca/cansim/a33?lang=eng\&spMode=master\&themelD=3867\&RT=TABLE

(12) Statistics Canada [Internet]. Population by year, by province and territory. 2014. http://www.statcan.gc.ca/tablestableaux/sum-som/I01/cst01/demo02a-eng.htm

(13) Naleway AL, Belongia EA, Kazmierczak JJ, Greenlee RT, Davis JP. Lyme disease incidence in Wisconsin: A comparison of state-reported rates and rates from a population-based cohort. Am J Epidemiol. 2002;155:1120-7.

(14) Leighton P, Koffi J, Pelcat Y, Lindsay LR, Ogden NH. Predicting the speed of tick invasion: An empirical model of range expansion for the Lyme disease vector Ixodes scapularis in Canada. J Appl Ecol. 2012;49:457-64.

(15) Ogden NH, Lindsay LR, Leighton P. Predicting the rate of invasion of the agent of Lyme disease, Borrelia burgdorferi in North America. J Appl Ecol. 2013;50:510-8. 
(16) Public Health Ontario [Internet]. 2013 Vector-borne Diseases: 2013 Summary Report. Toronto, ON: Queen's Printer for Ontario; 2012.

http://www.publichealthontario.ca/en/eRepository/Vector_Borne_Diseases_Summary_Report_2013.pdf.

(17) Falco RC, McKenna DF, Daniels TJ, Nadelman RB, Nowakowski J, Fish D, et al. Temporal relation between Ixodes scapularis abundance and risk for Lyme disease associated with erythema migrans. Am J Epidemiol. 1999;149:7716.

(18) Salkeld DJ, Castro MB, Bonilla D, Kjemtrup A, Kramer VL, Lane RS, et al. Seasonal activity patterns of the western black-legged tick, Ixodes pacificus, in relation to onset of human Lyme disease in northwestern California. Ticks Tick Borne Dis. 2014;5:790-6.

(19) Centers for Disease Control and Prevention. Three sudden cardiac deaths associated with Lyme carditis - United States, November 2012-July 2013. MMWR Morb Mortal Wkly Rep. 2013;62:993-6.

(20) Mechai S, Margos G, Feil EJ, Lindsay LR, Ogden NH. Phylogeographic analysis reveals a complex population structure of Borrelia burgdorferi in southern Canada. Appl Env Microbiol. 2015; In press. 


\section{Appendix 1: Data collected in national surveillance for Lyme disease in Canada during the period 2009 to 2012}

\begin{tabular}{|c|c|c|}
\hline Data description & Data type & Provinces supplying data \\
\hline Age & Continuous & All \\
\hline Sex & Male/Female & All \\
\hline Case classification & Confirmed/Probable & $\mathrm{AB}, \mathrm{SK}, \mathrm{MB}, \mathrm{ON}, \mathrm{PEI}, \mathrm{NS}, \mathrm{NL}$ \\
\hline Episode date & Day, Month, Year & All \\
\hline Type of episode date $^{1}$ & $\begin{array}{l}\text { Category: Onset/Sample } \\
\text { collection/Diagnosis/Report }\end{array}$ & $\mathrm{MB}, \mathrm{ON}, \mathrm{NB}, \mathrm{NS}, \mathrm{PEI}^{5}$ \\
\hline Travel outside Canada & Yes/No & $\begin{array}{c}\mathrm{AB}, \mathrm{SK}, \mathrm{MB}, \mathrm{ON}, \mathrm{NB}, \mathrm{PEI}, \mathrm{NS}, \\
\mathrm{NL}\end{array}$ \\
\hline $\begin{array}{l}\text { Exposure to known endemic area in } \\
\text { Canada within last } 30 \text { days }{ }^{1}\end{array}$ & Yes/No & $\mathrm{MB}, \mathrm{ON}, \mathrm{NB}, \mathrm{NS}$ \\
\hline $\begin{array}{l}\text { Name/identifier of endemic area in } \\
\text { Canada }^{1}\end{array}$ & Geolocator & \\
\hline $\begin{array}{l}\text { Exposure to known endemic area outside } \\
\text { Canada within last } 30 \text { days }{ }_{1}\end{array}$ & Yes/No & $\mathrm{MB}, \mathrm{ON}, \mathrm{NB}, \mathrm{NS}$ \\
\hline $\begin{array}{l}\text { Name/identifier of endemic area outside } \\
\text { Canada }^{1}\end{array}$ & Geolocator & $\mathrm{MB}, \mathrm{ON}, \mathrm{NB}, \mathrm{NS}$ \\
\hline $\begin{array}{l}\text { Forward sortation area of residence (FSA: } \\
\text { the first three digits of postal code) })^{1,2}\end{array}$ & Geolocator & $\mathrm{MB}, \mathrm{ON}, \mathrm{NB}, \mathrm{NS}$ \\
\hline $\begin{array}{llll}\text { Symptoms of early } & \text { Lyme } & \text { disease } \\
\text { (erythema migrans) } & & & \\
\end{array}$ & Yes/No & $\mathrm{MB}, \mathrm{ON}, \mathrm{NB}, \mathrm{NS}$ \\
\hline Symptoms of disseminated Lyme disease $^{1}$ & Yes/No & $\mathrm{MB}, \mathrm{ON}, \mathrm{NB}, \mathrm{NS}$ \\
\hline $\begin{array}{l}\text { Symptoms of disseminated Lyme disease: } \\
\text { Bell's palsy }{ }^{1}\end{array}$ & Yes/No & $\mathrm{ON}, \mathrm{NB}, \mathrm{NS}^{1}$ \\
\hline $\begin{array}{l}\text { Symptoms of disseminated Lyme disease: } \\
\text { other neurological symptoms }\end{array}$ & Yes/No & $\mathrm{ON}, \mathrm{NB}, \mathrm{NS}^{1}$ \\
\hline $\begin{array}{l}\text { Symptoms of disseminated Lyme disease: } \\
\text { cardiac symptoms }\end{array}$ & Yes/No & $\mathrm{ON}, \mathrm{NB}, \mathrm{NS}^{1}$ \\
\hline $\begin{array}{l}\text { Symptoms of late Lyme disease: Recurrent } \\
\text { arthritis/joint swelling }\end{array}$ & Yes/No & $\mathrm{ON}, \mathrm{NB}, \mathrm{NS}^{1}$ \\
\hline Method of diagnosis ${ }^{1}$ & Category: Serology/PCR/Culture & $\mathrm{MB}, \mathrm{ON}, \mathrm{NB}, \mathrm{NS}^{*}$ \\
\hline
\end{tabular}

1 Data collected in the Lyme Disease Enhanced Surveillance system are indicated by an asterisk, otherwise data were collected via the National Notifiable Disease Surveillance System.

2 Forward Sortation Area of residence was considered the location of acquisition in the absence of recorded travel or exposure history to a known Lyme disease risk area in Canada or abroad.

3.Radiculoneuropathy, encephalitis, lymphocytic meningitis, and encephalomyelitis.

4.Atrioventricular heart block and myocarditis

5 PEI provided Lyme Disease Enhanced Surveillance data elements for 2012 in August 2014; therefore this information was not included in this analysis. Abbreviations: AB: Alberta, SK: Saskatchewan, MB: Manitoba, ON: Ontario, NB: New Brunswick, NS: Nova Scotia, PEI: Prince Edward Island, NL: Newfoundland and Labrador 